\title{
Becoming adults in Britain: lifestyles and wellbeing in times of social change
}

\author{
Ingrid Schoon \\ Institute of Education, University of London \\ I.Schoon@ioe.ac.uk \\ Meichu Chen \\ University of Michigan, USA \\ Dylan Kneale \\ Institute of Education, University of London \\ Justin Jager \\ National Institute of Child Health and Human Development, USA
}

\section{Abstract}

This study examines variations in the combination of social roles in early adulthood and their association with mental health, subjective wellbeing, and alcohol use in two nationally representative British birth cohorts, born in 1970 $(n=9,897)$ and $1958(n=9,171)$. Using latent class analysis (LCA) we develop a typology of variations in the combination of educational attainment, employment status, housing, relationship and parenthood status of cohort members in their mid-twenties. We also assess the role of early socialisation experiences and teenage life planning as predictors of these status role combinations, and link transition outcomes by age 26 to measures of alcohol use, mental health and wellbeing. In both cohorts we identified five distinct profiles: 'work-orientation without children', 'traditional families', 'fragile families', 'highly educated without children', and 'slow starters'. These profiles are predicted by family social background, gender, own educational expectations and exam performance at age 16. The findings suggest that in both cohorts, high levels of life satisfaction are associated with either 'work orientation without children' or 'traditional family' life, suggesting that there are different transition strategies enabling individuals to become well-adjusted adults.

\section{Introduction}

The aim of this paper is to understand successful transitions to independent adulthood. In particular, we assess the extent to which variations in developmental transitions are associated with markers of subjective wellbeing, i.e. variations in levels of life satisfaction, psychological distress, and alcohol use. We ask in what circumstances diverging life courses and new demands on young people's resources are too extensive and sometimes overwhelming, or when are they are opening up new opportunities and life chances. The research is guided by assumptions formulated within a life course theory of human development in context (Bronfenbrenner 1979), taking into account multiple influences from across domains, as well as mutual selection and accommodation of individuals and their contexts (Baltes 1990; Elder 1998; Schulenberg, Sameroff and Cicchetti 2004).

In previous research, the association between variations in developmental transitions and mental health has been examined on the basis of the 'developmental match/mismatch model', specifying variations in the match between person-context characteristics (Eccles, Lord, Roeser, Barber and 
Hernandez-Jozefowicz 1997; Schulenberg and Maggs 2002; Schulenberg O'Malley, Bachman and Johnston 2005). According to this model, transitions that provide a progressive increase in developmentally appropriate challenges, through which young people can experience competence, enable the individual to successfully master the transition. If, however, the demands of the developmental transitions are not matched to the capabilities of the individual, or if they amplify previous difficulties, then there can be a negative effect on mental health and wellbeing. This can, for example, be the case if there is an 'overload', overwhelming the young person's coping capacities; if the transition exacerbates pre-existing differences (increased heterogeneity); or if it increases vulnerability to chance events exposure (heightened vulnerability). For a more detailed description of variations in how young people negotiate multiple developmental transitions - see Schulenberg and Maggs (2002).

While previous research has mostly focused on only one transition, in this study we examine how transitions across different domains weave together in people's lives by using a person-centred approach (Magnusson, Bergmann and El-Khouri 2003). We seek to identify a typology of transition patterns, and furthermore, aim to establish the meaning of distinct patterns of transitions by comparing different groups on a range of background variables (i.e. gender, ethnicity, family social status), individual characteristics (education aspirations, school motivation and academic attainment), as well as indicators of alcohol use and subjective wellbeing in adulthood (life satisfaction and psychological distress).

\section{The transition to independent adulthood}

The transition to independent adulthood is a developmentally dense period, involving multiple and inter-related social role changes across the 'big five' role transitions, including completion of fulltime education, entry into paid employment, independent living arrangements, and the step into family formation and parenthood (Shanahan 2000). These transitions are strongly interrelated, and completing most, if not all of these role transitions is often considered to be the marker for reaching independent adulthood (Macmillan and Eliason 2003; Shanahan, Porfeli, Mortimer and Erickson 2005; Schulenberg, Bryant and O'Malley 2004).
Recent studies have adopted a person-centred approach to gain a better understanding of how different roles combine within individuals at a particular life stage (Garrett and Eccles 2009; Oesterle, Hawkins, Hill and Bailey 2010; Osgood, Ruth, Eccles, Jacobs and Barber 2005; Ross, Schoon, Martin and Sacker 2009; Sandefur, Eggerling-Boeck and Park 2005; Schoon, Ross and Martin 2009). These studies were able to identify theoretically meaningful patterns of role combinations, and were able to show that these patterns relate to differences in social background variables and the wider socio-historical context.

\section{Transitions in context}

Life course transitions are set in a socio-cultural context and therefore can vary in timing, content and meaning (Elder and Shanahan 2007; Schoon and Silbereisen 2009). There are culturally based, age-related expectations regarding the timing and sequencing of major life transitions, providing a normative timetable (Heckhausen 1999) or scripts of life (Buchmann 1989). Such normative patterns are, however, subject to change, often brought about through influences from the wider sociohistorical context in which these transitions are embedded (Elder, Johnson and Crosnoe 2004). For example, since the mid-1970s, young people in industrialised nations have experienced rapid and profound social and cultural transformations, associated with an extended period of full-time education and delay in family formation (Blossfeld 2005; Bynner 2001; Shanahan 2000). The period between ages 18 and 25 years, during which young people explore new social roles, has been identified as a distinct developmental stage of emerging adulthood (Arnett 2000), although there is some debate as to whether all young people do indeed follow a similar time-table in their transition to independence, or whether there is a differentiation of transition experiences due to persisting social structures (Bynner 2005; Cohen, Kasen, Chen, Hartmark and Gordon 2003). It has been argued that there is a differentiation between those who take a slower route, i.e. those who participate in higher education and postpone adult transitions, and those who follow the traditional fast track transitions of leaving school early (Bynner 2005; Jones 2002; Schoon et al 2009). While many studies have focused on 'delayed transition', less is known about how those who leave school early succeed in 
life, and they have been referred to as the 'forgotten half' (Birdwell et al 2011; Halperin 1998; Symonds et al 2011).

\section{Predictors of life course transitions}

In this study we use two nationallyrepresentative birth cohorts born in 1958 and 1970, focusing on the transitions made by age 26 , to gain a better understanding of experiences of young people coming of age in a changing socio-historical context.

According to the theory of the second demographic transition, there has been an 'ideational shift' since the 1970s, characterised by changing social practices and the breakdown of many class, gender, and age-based constraints shaping demographic events (Lesthaeghe 1995). The 1958 cohort was born just before this major demographic shift, while the 1970 cohort grew up during this period, enabling us to take into account changing demands and opportunities.

It has been argued that individual biographies have become more removed from traditional life scripts and more dependent on individual decision making (Beck and Beck-Gernsheim 2002; Giddens 1991). The notion of individual choice has however been questioned, as there is persisting evidence of unequal access to educational and career opportunities (Bynner 2005; Furlong and Cartmel 1997; Heinz 2002). Young people from less privileged family backgrounds, especially women, tend to make work and family-related transitions earlier than their more privileged peers, with reduced career opportunities in later life (Osgood et al 2005; Ross et al 2009; Sandefur et al 2005; Schoon, Martin and Ross 2007). They furthermore have lower aspirations regarding education and employment transitions, show lower levels of school motivation, and obtain fewer educational qualifications (Schoon 2007). There is also evidence that family instability, indicated for example by parental divorce or separation, influences the timing and sequencing of transition experiences and adult outcomes (Amato and Booth 1997; Furstenberg 2000; Ross et al 2009). This interplay between structural factors and individual choice has been described by the term 'bounded agency' (Shanahan 2000). Although social change has affected all young people, it has not affected all in the same way. Based on previous research we expect a persisting influence of social background characteristics on both individual agency processes as well as status attainment in early adulthood (Ross et al 2009; Schoon et al 2009).

\section{Variations in wellbeing}

Developmental progression and the mastery of age-specific role transitions has been linked to increased levels of subjective wellbeing and low symptomatology (Schulenberg, Bryant et al 2004; Seiffge-Krenke and Gelhaar 2008). The more success and less stalling in the domains of work and romantic involvement, the greater the likelihood of maintaining high levels of wellbeing (Schulenberg et al 2004). Problems in establishing oneself in the labour market or making the transition into independent living, have been associated with lower levels of life satisfaction and health (Kins et al 2010; Schoon et al 2009) and potentially harmful behaviour, such as frequent alcohol use (Schulenberg et al 2005; Staff et al 2010). Romantic involvement with a partner is generally associated with higher levels of wellbeing, while early parenthood has been associated with negative effects on wellbeing (Nomaguchi and Milkie 2003; Kiernan 1997; Henretta 2007), largely due to relationship instability and fewer socio-economic resources. On the other hand, it has been argued that early transitions can be beneficial for certain individuals (Booth et al 2008), and the effects of parenthood on wellbeing depend on gender and marital status, as well as other circumstances in life (Nomaguchi and Milkie 2003; Woo and Raley 2005; Keeton et al 2008). Furthermore, the time frame for achieving most of the developmental demands might have expanded for the later-born cohort (Arnett 2000), and the more recent cohort might feel more relaxed about not fulfilling all five transition demands by age 26 , in particular, regarding the step into parenthood. For example, in a recent study drawing on data from the Seattle Social Development Project, childlessness has been shown to have few costs for psychological wellbeing, and has even been associated with enhanced wellbeing (Umberson et al 2010).

The socio-historical context in which transitions are embedded shapes the expectations, meaning and experience of transition outcomes, and for a better understanding of what makes a 'successful transition' we have to examine multiple interacting transitions in context. In the present study, we examine two indicators of subjective wellbeing: life 
satisfaction and low levels of psychological distress, as well as frequency of alcohol use, capturing key positive aspects of transition outcomes, i.e. being satisfied with one's life and the absence of major disorders or problem behaviours.

\section{Aims and Hypotheses}

This study has four aims:

First we aim to identify patterns and variations in the combination of social roles in early adulthood, taking into account interactions between transition outcomes in education, work, housing, family formation and parenthood. We expect to find meaningful combinations of transition outcome across the 'big five' domains. In particular we expect to find evidence of 'fast' versus 'slow' transitions to adulthood.

Second, we assess the role of early precursors in predicting variations in role combinations. We expect that variations in transition outcomes are associated with social background factors, such as gender, family background and family stability, as well as individual aspirations and school attainment. Young people from less privileged backgrounds, in particular women, are expected to be more likely to undergo fast transitions, i.e. leaving school after completion of compulsory schooling and making the step into family formation at an earlier age, while young people from more privileged backgrounds are expected to be more likely to follow slow track transitions, characterised by extended education and delay of partnership and parenthood.

Third, we expect that levels of wellbeing vary for different subgroups in the population and are associated with variations specified according to the developmental match/mismatch model. In cases where the developmental transitions are matched to the capabilities and resources of the individual, we expect high levels of wellbeing. In cases where there is a mismatch or overload, we expect reduced levels of wellbeing.

Fourth, we examine whether: a) similar patterns of role combinations apply in two birth cohorts born 12 years apart: b) there is a shift towards more extended or slower transitions in the later-born cohort: c) in the later-born cohort a delay in assumption of adult roles, or a moratorium period, is associated with higher levels of wellbeing than the traditional fast track transitions.

\section{Method}

\section{Sample}

The study used data collected for the 1958 National Child Development Study (NCDS) and the 1970 British Cohort Study (BCS70), two of Britain's richest research resources for the study of human development (Ferri, Bynner and Wadsworth 2003). NCDS took as its subjects, all persons living in Great Britain who were born in one week in March 1958. In six follow-up surveys, data were collected on the physical, psycho-social and educational development of the cohort at age 7, 11, 16, 23, 33, 42, 46 and 50 years. The BCS70 has followed children born in one week in April 1970. Follow-up surveys have taken place when the cohort members were aged 5,10 , $16,26,30,34$, and 38 years. In both cohorts, the sample population is predominantly white (about 3 to 4 per cent are from Indian, Pakistani, Bangladeshi, African, Caribbean, Chinese or mixed origin), reflecting the ethnic diversity of the UK population at the time (Ferri et al 2003).

The analysis is based on cohort members with complete data on transition outcomes at age 26, including 9,171 cohort members in NCDS and 9,897 in BCS70. An analysis of response bias showed that the achieved samples in the age 30/33 sweeps did not differ from the target sample across a number of critical variables (social class, parental education, and gender), despite a slight under-representation of males, and of the most disadvantaged groups (Plewis et al 2004).

\section{Measures}

Status indicators in the mid-20s include partnership status, parenthood, housing, economic activity, and highest qualifications (see Table 1). The information was derived from retrospective education-, employment-, housing- and family history data, collected from cohort members in their early 30 s (i.e. at age 33 in NCDS and age 30 in BCS70).

\section{Predictor Variables}

Parental social status at birth was measured by the Registrar General's measure of occupational social class (RGSC), assessed by the current or lastheld job of the cohort member's father. Where the father was absent, the social class (RGSC) of the mother was used. For the purpose of this analysis, RGSC is coded as: I and II- managerial and professional; III - skilled manual or non-manual; IV 
and V - semi- or unskilled (Leete and Fox 1977). We also included a measure of mother's and father's education, differentiating between parents who left school at the minimum age or stayed on.

Family stability indicating whether the cohort member had experienced parental divorce, separation or death of a parent by age 10 for BCS70, and age 11 for NCDS.

Educational plans of the cohort members when aged 16, indicated whether they wished to continue in further education.

School motivation at age 16 was assessed with a 5-item academic motivation scale (e.g. "school is largely a waste of time"; "I do not like school"). Items were measured on a 5-point Likert scale. Internal consistency of the scale is satisfactory (Cronbach's alpha: $\alpha=.77$ in NCDS, and $\alpha=.76$ in BCS70), and scores were $z$-standardised. The validity of the school motivation scale has been established in previous studies, showing significant correlations between school motivation and educational aspirations (Schoon et al 2007) and time spent in education (Schoon 2008). A high score indicates positive school motivation, and a low score, school disengagement.

Academic attainment at age 16 is measured by an overall 'exam score', calculated for both cohorts from their examination performance at age 16 . The examination system was the same for both cohorts. The overall exam scores range from 0 to 94 in NCDS, and from 0 to 97 in BCS70.

Indicators of Adult Wellbeing include measures of mental health and life satisfaction. These measures were obtained for BCS70 cohort members at age 26 and 30, while for NCDS they are only available at age 33 , but not age 26 . We are thus able to assess concurrent associations between transition outcomes and wellbeing in BCS70, and use transition outcomes at 26 to predict wellbeing at a later time point in both cohorts.

Adult mental health was measured with the Malaise Inventory (Rutter, Tizard and Whitmore 1970), a self-completion measure of psychological distress, or depression, which has been widely used in general population studies (McGee et al 1986; Rutter and Madge 1976; Rodgers et al 1999). The internal consistency of the scale has been shown to be acceptable and the validity of the inventory shown to hold in different socio-economic groups (Rodgers et al 1999). The overall scale score ranges from 0 to 24. Individuals scoring affirmatively on 8 or more of the 24 items are considered to be at risk of depression.

Life satisfaction was assessed with one item: 'On a scale from 0 to 10 how satisfied are you about the way your life has turned out so far?' ( $0=$ extremely unsatisfied to $10=$ completely satisfied).

Frequency of alcohol use was measured with a question that asked respondents, 'How often do you have an alcoholic drink of any kind?' From the responses, a dichotomous variable was created in which respondents who reported daily drinking were compared to those who drank on fewer occasions.

\section{Data analysis}

We use Latent Class Analysis (LCA) as implemented in MPlus 6.1 (Muthén and Muthén 2007) to identify how different indicators of adult roles combine within individuals. LCA is a statistical method that enables us to examine latent structures among a set of categorical scored variables, and to identify underlying types or classes (Goodman 1974; Lazarsfeld and Henry 1968). A number of latent classes are identified that adequately capture the structure in the data, and parameters estimated that give the proportions of individuals within each of the latent classes (latent class probabilities) and their distribution across the indicator variables within these classes (conditional probabilities). Parameters are estimated using maximum likelihood criterion where the estimates are those most likely to account for the observed data (Clogg 1995). The model fit is determined by the Schwarz's Bayesian Information Criterion (BIC) (Schwarz 1978), a commonly-used fit index that balances model fit with model parsimony, adjusting for the size of the sample. The model with the lowest BIC is considered optimal (Muthén and Muthén 2000). We also consider the quality of the classification. The entropy index, an aggregate measure of classification, uncertainty-based on the average posterior probabilities (i.e. probability of an observations to be classified in a given class), is used to indicate how well a model classifies individuals (Dias and Vermunt 2006). It ranges from 0 to 1 , with 1 indicating that all individuals have a probability of 1 for being in one class, and a probability of zero for being in all other classes. For well-separated latent classes, the entropy index is close to 1 , while for ill-separated classes it is close 
to 0 . We furthermore consider the usefulness of the solution in practice, determined by the interpretability of the classes, the number of individuals in each class, and the emergence of distinct patterns regarding associated predictors and consequences.

The associations between predictors and class memberships were estimated by multinominal logistic regression. The association between class membership and indicators of wellbeing were assessed using analysis of variance. To address the issue of missing data, the analysis was run using the full information maximum likelihood (FIML) approach as implemented in Mplus6 (Muthén and Muthén 2009) using full information maximum likelihood (FIML) estimation to handle any item non-response (Asparouhov and Muthén 2009). FIML is preferable to maximum likelihood estimation based on complete data (the listwise deletion (LD) approach) since FIML estimates will tend to show less bias and be more reliable than LD estimates, even when the data deviate from missing at random and are non-ignorable (Arbuckle 1996).

\section{Results}

Table 1. Observed role characteristics at age 26

\section{NCDS in $1984 \% \quad$ BCS70 in $1996 \%$}

\section{Education}

No qualifications

Up to GCSE/O-level

12.1

49.0

A-level (baccalaureate)

Degree level

\section{Employment status}

Unemployed/Out of the labour force

Full-time home maker

Full-time education

Works part-time

Works full-time

\section{Living arrangements}

Lives with parents

Rented accommodation

Own home

\section{Relationship status}

\author{
Married \\ Cohabiting
}

Single

\section{Parental status}

Childless

1-2 children

3 or more children

17.3

21.7

18.7

$\begin{array}{cc}4.4 & 4.1 \\ 12.2 & 9.4 \\ 1.1 & 3.2 \\ 5.7 & 7.6 \\ 76.6 & 75.7\end{array}$


Table 1 gives distributions of the five status indicators of education, employment, living arrangements, relationship and parenthood status at age 26 for each of the cohorts. The later-born BCS70 cohort achieved higher academic qualifications than the earlier-born NCDS cohort at the same age, yet also had more young people leaving education without any qualifications. The later-born cohort comprises fewer full-time home makers, more part-time workers, or cohort members still in full-time education at age 26 . In both cohorts about the same percentage of young people are living with their parents at age 26 . In the 1958 cohort, more young people own their own home by age 26 , while in the 1970 cohort, more are living in rented accommodation. Fewer in the laterborn cohort are married and have children. The findings seem to indicate a trend towards delayed assumption of family roles in the later-born cohort, yet also an increasing polarization regarding education and housing transitions.

Table 2. Model fit indices and entropy by number of classes from exploratory latent class analysis (LCA) of role configurations

\begin{tabular}{crrrr|rrrr}
\multicolumn{4}{c|}{ NCDS 1984 (N=9,171) } & \multicolumn{4}{c}{ BCS70 1996 (N=9,897) } \\
\hline Class & LL & \# Par & BIC & Entropy & LL & \# Par & BIC & Entropy \\
2 & -40773 & 27 & 81792 & 0.836 & -46481 & 27 & 93210 & 0.826 \\
3 & -39397 & 41 & 79167 & 0.813 & -45134 & 41 & 90645 & 0.786 \\
4 & -39138 & 55 & 78778 & 0.784 & -44808 & 55 & 90122 & 0.754 \\
$\mathbf{5}$ & -38916 & $\mathbf{6 9}$ & $\mathbf{7 8 4 6 1}$ & $\mathbf{0 . 7 6 4}$ & -44558 & $\mathbf{6 9}$ & $\mathbf{8 9 7 5 1}$ & $\mathbf{0 . 7 5 9}$ \\
6 & -38863 & 83 & 78483 & 0.761 & -44483 & 83 & 89729 & 0.742 \\
7 & -38823 & 97 & 78532 & 0.699 & -44426 & 97 & 89745 & 0.741 \\
\hline
\end{tabular}

Notes.

LL: Log-Likelihood value for the $k^{\text {th }}$ model

\# Par: Numbers of parameters in the $k^{\text {th }}$ model

$C F$ : Scale correction factors for MLR in the $k^{\text {th }}$ model

BIC: Bayesian Information Criteria

\section{Identification of (latent) class membership}

Table 2 gives the indicators of model fit for the different k-class solutions. Although the lowest BIC was represented by a 6 -class solution for BCS70, there was little relative improvement beyond a 5class solution for both cohorts, differentiating between 'traditional families', 'career orientation without children', 'slow starters', 'fragile families', and those who are 'highly educated without children'. Inspection of solutions with greater than five classes did not reveal any qualitatively different configurations, or they were simply not interpretable. For example, in both cohorts we find a 'single mothers' group emerges from the group of fragile families, which although it differs from the former according to partnership status and gender, showed no further variation amongst the other predictors in the model. In addition, some further classes revealed a splitting of both traditional families and fragile families into male and female equivalent classes. Simulation studies have shown that BIC tends to overestimate the optimum number of classes (Nylund, Asparouhov and Muthen 2007). To test the reliability of our solution, we re-ran the model with different starting values and with a randomly-selected sample of approximately $25 \%$ (2,500 cases) in both cohorts. We were able to replicate the 5 -class solutions exactly, while solutions with additional classes were not stable. In addition, with a reduced sample, BIC also supported the 5 -class solutions. 
Table 3. Proportion of cohort members allocated to each of the five classes

\begin{tabular}{l|c|c} 
& NCDS in 1984 \% & BCS70 in 1996\% \\
\hline Work orientation without children (WWC) & 31.4 & 32.2 \\
Traditional families (TF) & 20.1 & 15.9 \\
Highly educated without children (EWC) & 18.0 & 23.1 \\
Slow starters (SS) & 17.4 & 15.9 \\
Fragile families (FF) & 13.0 & 12.9 \\
N & 9,171 & 9,897 \\
\hline
\end{tabular}

Table 3 indicates the proportion of cohort members that were allocated with the highest probability to each of the five classes (the class size parameters fitted by the model). In both cohorts 'work orientation without children' is the largest group, especially in later-born 1970 cohort, followed by those in 'traditional families' for the 1958 cohort and the 'highly educated without children' in the 1970 cohort. There are similar rates of 'slow starters' and 'fragile families' in both cohorts.

Table 4. Latent class probabilities for both cohorts

\begin{tabular}{|c|c|c|c|c|c|c|c|c|c|c|}
\hline & \multicolumn{5}{|c|}{ NCDS at age 26 in $1984(N=9,171)$} & \multicolumn{5}{|c|}{ BCS70 at age 26 in $1996(\mathrm{~N}=9,897)$} \\
\hline & WWC & $\mathrm{TF}$ & EWC & SS & FF & WWC & $\mathrm{TF}$ & EWC & SS & $\mathrm{FF}$ \\
\hline \multicolumn{11}{|l|}{ Education } \\
\hline No qualifications & .047 & .118 & .047 & .139 & .392 & .092 & .179 & .098 & .134 & .401 \\
\hline Up to GCSE/O-level & .470 & .659 & .313 & .498 & .523 & .425 & .617 & .294 & .450 & .516 \\
\hline A-level (baccalaureate) & .235 & .099 & .214 & .187 & .057 & .169 & .117 & .119 & .145 & .062 \\
\hline Degree level & .249 & .123 & .426 & .176 & .028 & .313 & .087 & .489 & .271 & .022 \\
\hline \multicolumn{11}{|l|}{ Employment status } \\
\hline Unemployed/Out of labour force & .009 & .034 & .042 & .077 & .103 & .005 & .011 & .075 & .043 & .120 \\
\hline Full-time home maker & .021 & .388 & .000 & .001 & .293 & .000 & .218 & .001 & .002 & .479 \\
\hline Full-time education & .004 & .001 & .043 & .005 & .001 & .010 & .005 & .098 & .030 & .010 \\
\hline Works part-time & .033 & .131 & .020 & .021 & .100 & .027 & .241 & .037 & .028 & .113 \\
\hline Works full-time & .932 & .447 & .894 & .896 & .502 & .958 & .524 & .789 & .897 & .278 \\
\hline \multicolumn{11}{|l|}{ Living arrangements } \\
\hline Lives with parents & .010 & .003 & .058 & .906 & .086 & .042 & .031 & .080 & 1.000 & .105 \\
\hline Rented accommodation & .095 & .226 & .622 & .049 & .891 & .129 & .214 & .881 & .000 & .850 \\
\hline Own home & .895 & .771 & .320 & .046 & .023 & .829 & .755 & .039 & .000 & .046 \\
\hline \multicolumn{11}{|l|}{ Relationship status } \\
\hline Married & .858 & .938 & .071 & .025 & .656 & .367 & .702 & .023 & .001 & .243 \\
\hline Cohabiting & .142 & .041 & .242 & .016 & .175 & .422 & .272 & .331 & .024 & .410 \\
\hline Single & .000 & .021 & .686 & .959 & .169 & .211 & .027 & .646 & .974 & .346 \\
\hline \multicolumn{11}{|l|}{ Parental status } \\
\hline Childless & .851 & .000 & .990 & .968 & .106 & .943 & .126 & .963 & .951 & .021 \\
\hline 1-2 children & .149 & .929 & .010 & .032 & .730 & .057 & .841 & .037 & .049 & .812 \\
\hline 3 or more children & .000 & .071 & .000 & .000 & .164 & .000 & .032 & .000 & .000 & .166 \\
\hline Class sizes $(\mathrm{N})$ & 2,884 & 1,847 & 1,653 & 1,593 & 1,194 & 3,187 & 1,574 & 2,285 & 1,577 & 1,274 \\
\hline
\end{tabular}

Note. WWC: Work-orientation Without Children; TF: Traditional Families; EWC: Highly educated without children; SS: Slow Starters; FF: Fragile Families 
Typology of role configurations in young adulthood

Table 4 presents the latent class and conditional probabilities of the final 5-class solutions in both cohorts. Whilst membership proportions have slightly changed from NCDS to BCS70, conditional probabilities and gender distributions follow a similar pattern, justifying the use of the same labels across cohorts:

Work orientation without children (WWC). Members of this group are typically full-time employed, have no children, and own their own home. Partnership status is different in the two cohorts, with most of those in the 1958 cohort being married, while in the later-born cohort this class includes married, cohabiting, and single individuals. Cohort members in this group are, on average, relatively well-educated, yet not as highly as the 'highly educated without children'.

Traditional Families (TF). Members of this group are typically married (although there are more cohabiting cohort members in the later-born cohort), own their own home, and have one or two children. The level of educational attainment varies, with the majority having obtained their O-level qualifications. Whilst nearly half of the members in this class are in full-time employment (mostly males), considerable proportions are full-time home makers or working part-time (mostly females).

Highly Educated Without Children (EWC). This group is the most highly educated (i.e. with degree level qualifications). Most of them are single with no children, working full-time, and living in rented accommodation (especially in the later-born cohort).

Slow Starters (SS). Slow starters are typically single, childless, and live with their parents. Most of them work full-time. Furthermore, their educational profile has slightly changed, with more individuals in the later-born cohort having degree-level qualifications. This group is however not as welleducated as those cohort members on the 'highly educated without children', or those in the class 'work without children'.

Fragile Families (FF). This class is characterized primarily by parenthood status, combined with a high likelihood of living in rented accommodation, and poor educational attainment. This class contains more people without any formal qualification than any other class. Compared to all other classes (except for 'traditional families' in the 1958 cohort), individuals in 'fragile families' are least likely to be in full-time employment.

\section{Antecedents of class membership}

Multinominal regression models were run to establish the association between the predictor variables and membership in any of the five groups. For ease of interpretation, the standard multinomial regression coefficients have been converted into relative risks, which eliminate the need for a reference class. The estimates presented in table 5 summarise the change in probabilities for being a member of each group, associated with a level change on the predictor variable (holding all other predictors constant at their means).

In both cohorts females are more likely to be grouped into the 'traditional family' or the 'fragile family' group than males. Additional predictors of entering the 'traditional family' group include having relatively low-educated parents and low educational plans. While NCDS members in this group show average exam scores, in BCS70 they are more likely to have low exam scores, indicating a shift in predictors and maybe different characteristics of the two groups. Regarding the 'fragile family' group, significant predictors besides gender include low parental social class, low parental education, low educational plans, low school motivation, and poor exam results at age 16.

In both cohorts, 'work-orientation without children' is associated high educational plans and good exam scores. Entry into the 'highly educated without children' group is predicted by being male, stemming from relatively advantaged family background with educated parents, having high educational plans and good academic attainment. Entry into the 'slow starter' group is significantly associated with being male, relatively privileged family background, experience of family break-up, and average, yet not low exam scores. 
Table 5. The estimated relative risks of being in a given class, computed from multinomial logistic regressions of class memberships at age $\mathbf{2 6}$ on early predictors for NCDS and BCS70

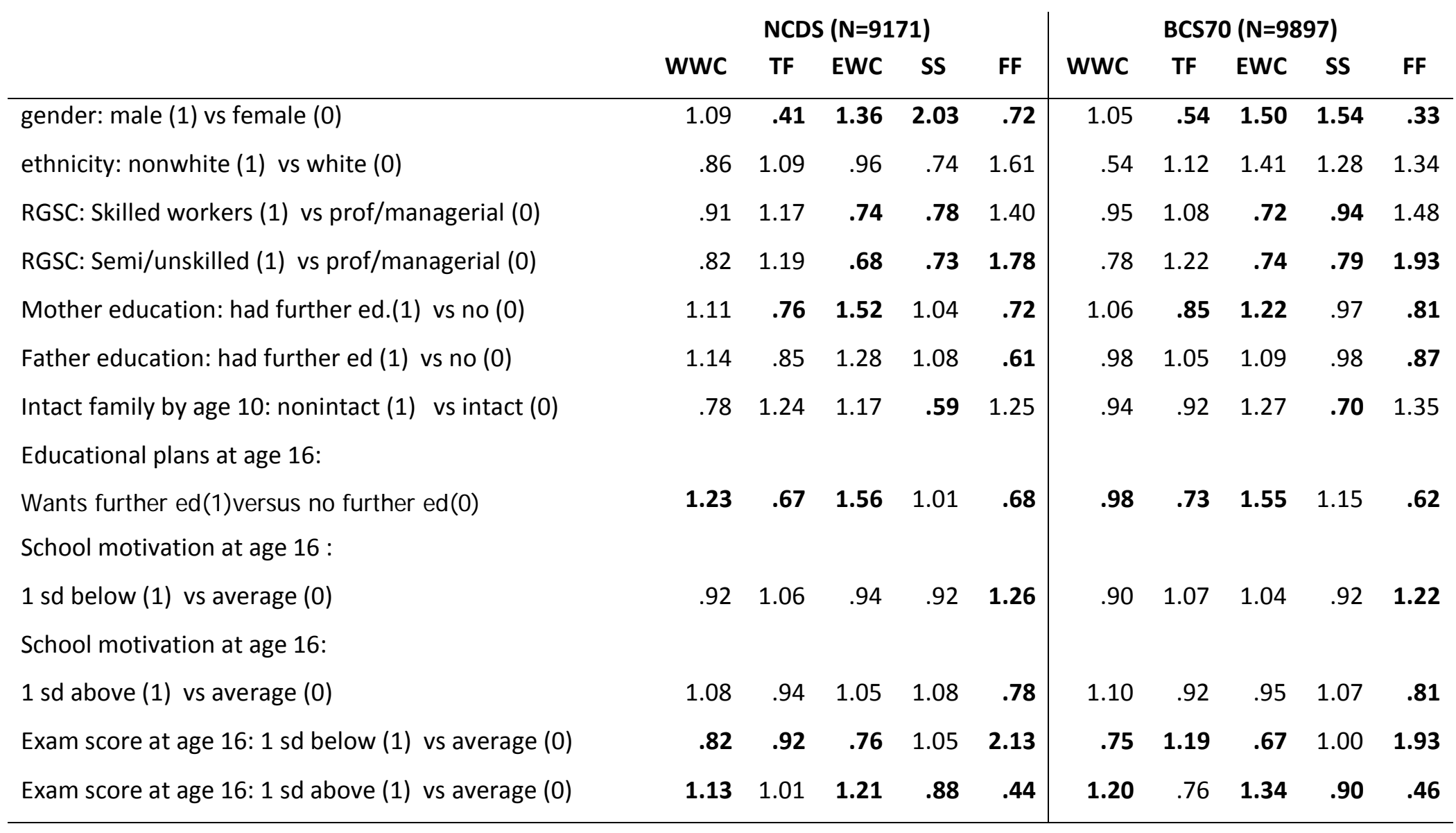

Note.

WWC:Work-orientation Without children; TF: Traditional Families; EWC: Highly educated without children; SS: Slow Starter; FF: Fragile Families Bold relative risks are significant at .01 level based on 99\% confidence interval of the estimated relative risk coefficients 
Table 6. Sample means and standard deviation of adult outcomes by class memberships and by cohorts
F-value (and pvalue) for class

differences

\begin{tabular}{|c|c|c|c|c|c|c|c|}
\hline \multicolumn{8}{|c|}{ NCDS } \\
\hline Classes & Overall & WWC & TF & EWC & SS & FF & \\
\hline Adult Outcomes & Mean (std) & Mean (std) & Mean (std) & Mean (std) & Mean (std) & Mean (std) & \\
\hline \multirow[t]{2}{*}{ Life satisfaction at 33} & 7.49 & 7.72 & 7.66 & 7.36 & 7.33 & 7.03 & 43.00 \\
\hline & $(1.66)$ & $(1.48)$ & (1.67) & $(1.60)$ & (1.67) & (1.99) & $(.000)$ \\
\hline \multirow[t]{2}{*}{ Malaise at 33} & 2.30 & 1.87 & 2.48 & 2.17 & 2.17 & 3.45 & 66.04 \\
\hline & $(2.87)$ & $(2.47)$ & $(2.98)$ & $(2.74)$ & (2.59) & $(3.72)$ & $(.000)$ \\
\hline \multirow[t]{3}{*}{ Daily alcohol use at 33} & .12 & .14 & .07 & .19 & .13 & .07 & 36.40 \\
\hline & $(.33)$ & $(.35)$ & $(.26)$ & $(.39)$ & $(.34)$ & $(.26)$ & $(.000)$ \\
\hline & \multicolumn{6}{|c|}{ BCS70 } & \\
\hline \multirow[t]{2}{*}{ Life satisfaction at 26} & 7.29 & 7.71 & 7.79 & 6.92 & 6.78 & 6.63 & 104.46 \\
\hline & $(1.85)$ & $(1.58)$ & $(1.71)$ & (1.94) & $(1.92)$ & $(2.10)$ & $(.000)$ \\
\hline \multirow[t]{2}{*}{ Life satisfaction at 30} & 7.35 & 7.62 & 7.54 & 7.18 & 7.36 & 6.71 & 60.41 \\
\hline & $(1.82)$ & (1.68) & $(1.76)$ & $(1.86)$ & (1.74) & (2.07) & $(.000)$ \\
\hline \multirow[t]{2}{*}{ Malaise at 26} & 3.74 & 3.41 & 3.68 & 3.67 & 3.67 & 5.41 & 43.76 \\
\hline & (3.26) & $(2.94)$ & (3.11) & (3.35) & (3.29) & (3.90) & $(.000)$ \\
\hline \multirow[t]{2}{*}{ Malaise at 30} & 3.49 & 3.01 & 3.37 & 3.60 & 3.35 & 4.89 & 63.99 \\
\hline & $(3.44)$ & $(2.97)$ & $(3.25)$ & (3.61) & $(3.26)$ & $(4.23)$ & $(.000)$ \\
\hline \multirow[t]{2}{*}{ Daily alcohol at 26} & .09 & .09 & .05 & .13 & .08 & .04 & 17.18 \\
\hline & $(.28)$ & $(.29)$ & $(.22)$ & $(.34)$ & $(.27)$ & (.19) & $(.000)$ \\
\hline \multirow[t]{2}{*}{ Daily alcohol at 30} & .13 & .14 & .10 & .19 & .11 & .06 & 34.91 \\
\hline & $(.34)$ & $(.35)$ & $(.30)$ & $(.39)$ & $(.31)$ & $(.24)$ & $(.000)$ \\
\hline
\end{tabular}

Note: WWC: Work-orientation Without Children; TF: Traditional Families; AT: Highly educated without children

SS: Slow Starter; FF: Fragile Families 


\section{Adult outcomes}

Analyses of variance were run to test differences in the wellbeing indicators across the five groups. In table 6 , the mean and standard deviation of the outcome variables are given for both cohorts, and for each of the five groups in each cohort. Life satisfaction is highest among cohort members in the 'work no children' class and those in the 'traditional families' class, followed by the 'highly educated without children' and the 'slow starter' classes. In NCDS, levels of distress are lowest among cohort members in the 'work no children' class, followed by the 'highly educated without children' and 'slow starters'. In BCS70, low levels of distress are reported also by cohort members in the 'work no children' class, followed by the 'slow starters', those in 'traditional families', and the 'highly educated without children'. In both cohorts those in the 'fragile families' class report the lowest levels of life satisfaction and the highest levels of distress. Daily alcohol use is highest among the 'highly educated without children' and lowest among cohort members who have made the step into parenthood, i.e. the 'traditional' and the 'fragile families'.

In interpreting these findings, it has to be kept in mind that information regarding adult outcomes in the 1958 cohort was collected seven years after the role combinations were assessed, i.e. at age 33 and not at age 26 . In the 1970 cohort, by contrast, all information was assessed at age 26 and again at age 30. We can thus examine concurrent associations between the outcome variables and the role combinations in BCS70, and in both cohorts we assess associations between transition outcomes at age 26 and later wellbeing. The pattern observed for the 1958 cohort can largely be confirmed in the later-born cohort: individuals grouped into the 'work no children' class at age 26 reported the highest level of life satisfaction and the lowest psychological distress later on, and those in the 'fragile families' class, the highest levels of distress and lowest levels of life satisfaction. Relatively low levels of distress are furthermore reported by the 'highly educated without children' and the 'slow starters', however the 'highly educated without children' reported more daily alcohol use than the other four groups. At age 26, life satisfaction is highest among cohort members in the 'traditional families' class, followed by those in the 'work no children', then the 'highly educated without children', then the 'slow starter' class.

\section{Summary and Conclusion}

In both cohorts, five distinct and meaningful groups could be identified, which relate well to earlier studies using LCA (Osgood et al 2005; Sandefur et al 2005; Ross et al 2009). The five groups have been labeled as 'work orientation without children', ' highly educated without children', 'traditional families', 'slow starters', and 'fragile families'. The most prevalent pattern in both cohorts is 'work orientation with no children', which also involves home ownership. In the later-born cohort there are more cohort members identified as 'highly educated without children' and fewer 'traditional families'. Both cohorts contain similar proportions of cohort members grouped into 'slow starters' and 'fragile families'. As in previous studies, our groups are characterized by variations in academic attainment, employment status and family formation - yet our groups are, in addition, clearly defined by their housing situation.

The five groups differed in their level of wellbeing. Those groups who reported the highest levels of life satisfaction, i.e. the 'work no children' and the 'traditional family' group, also owned their own homes, suggesting that home ownership plays a role in shaping wellbeing. The association between home ownership and wellbeing might be a particular British phenomenon, yet it illustrates the need of young people to establish their independence. 'Fragile families' as well as the 'highly educated without children', typically lived in rented accommodation, suggesting that home ownership is a possible indicator of having achieved financial security. 'Slow starters' still lived in, or had returned to, their parental home by age 26 . The group of 'slow starters' can possibly be seen to representing those cohort members who are in an extended period of exploration characterizing emerging adulthood (Arnett 2000). This group is however not a majority pattern, and has not increased for the later-born cohort (comprising about 18 per cent in the 1958 cohort and $15 \%$ in the 1970 cohort). Neither do they show the highest levels of wellbeing, suggesting that delaying the step into independence is associated with reduced life satisfaction. 
Regarding cohort differences, we find that the later cohort is growing up with better educated parents and are better educated themselves, i.e. have obtained higher level qualifications. In the later-born cohort, family formation has been delayed and fewer young people are home owners by age 26. We also find higher levels of psychological distress and lower levels of life satisfaction in the later-born cohort, which might be associated with the reduced likelihood of home ownership or delays in partnership formation. There were no large cohort changes regarding daily alcohol use. Generally, our findings suggest only slight cohort changes regarding role combinations by age 26 , driven particularly by extended education participation and delay in family formation. However, by age 26 the majority of young people in the UK are living together as a couple (i.e. are married or cohabiting). We therefore cannot confirm the assumption of a new normative stage of non-commitment as suggested by Arnett (2000), neither is there a majority of young people with extended education, i.e. the 'highly educated without children'. The findings rather point towards a polarization of fast versus slow transitions, with the fragile and traditional families having made an early step into parenthood (before the age of 26), and the 'slow starters' and the 'highly educated without children' having delayed the assumption of adult responsibilities. Those who are 'work oriented without children' are in-between. As predicted, cohort members with delayed transitions were more likely born into relatively privileged families, in particular the "highly educated without children'. Fast transitions, in contrast, are associated with a less privileged family background and being female. Furthermore, compared to those with extended transitions, those on the fast track show relatively fewer individual resources, as for example lower levels of education aspirations, school motivation, and academic attainment.

It is thus no surprise that cohort members in the 'fragile family' group report low levels of wellbeing, i.e. low levels of life satisfaction and high levels of psychological distress. Their transition fits the overload model (Schulenberg and Maggs 2002), where the experience of multiple transitions over a relatively short period of time has possibly overwhelmed their coping capabilities. Fast track transitions can however also be successfully mastered, as indicated by the high levels of life satisfaction among individuals in the 'traditional family' group. Individuals in the 'traditional family' group have successfully navigated all five transitions, suggesting the experience of a progressive increase in developmentally appropriate demands. They have successfully negotiated the step into financial independence, have established a stable relationship, overcame the risks associated with relatively early parenthood, and have succeeded in getting onto the property ladder. They report slightly higher levels of distress than the 'work no children' group, possibly reflecting the strain of looking after young children.

Those grouped into the 'work-orientation without children' group have mastered four out of five transitions, i.e. all transitions but the step into parenthood. Their experience can possibly also be conceptualized as a progressive increase in role demands: for young people in this group, the timing and sequencing of transition to adult roles appears to match their capabilities and resources, and has opened up developmentally appropriate challenges. In both cohorts, this group shows high life satisfaction and low levels of distress. They are also less likely to drink daily than the 'highly educated without children', maybe another indicator of less distress.

Delaying commitment to adult roles is, in our study, associated with slightly reduced levels of wellbeing. Compared to the 'traditional family' and 'work no children' groups, the 'highly educated without children' might have channeled their energies in pursuing a trajectory that enabled them to focus on maximizing existing strengths within one domain. As teenagers they already showed a preference for an academic career: they wanted to pursue further education and achieved good exam results at age 16 . They furthermore grew up in relatively privileged families with highly educated parents. Their transition could thus be characterized by the increased heterogeneity model (see Schulenberg and Maggs 2002), where transitions magnify existing strengths. By age 26 they express moderate to low levels of wellbeing, especially in the later-born cohort, and are most likely to drink daily. It could be that focusing on only two transitions, i.e. education and work, without establishing a stable relationship or making the step onto the housing ladder does not provide a 
sufficiently sturdy base for wellbeing (see also Garret and Eccles 2009). Furthermore, in both cohorts the 'slow starter' group shows relatively low levels life satisfaction, possibly indicating conflicting demands or a problematic childhood. They grew up in relatively privileged families, yet might have experienced the separation of their parents. Their academic attainment was average, suggesting that the transition demands might not have matched their psycho-social capabilities. They only 'succeeded' in making two of the 'big five' transitions, i.e. completing education and entering paid employment.

The findings suggest that delay in commitment as well as a mismatch between transition demands and individual capabilities and resources, is associated with lower levels of wellbeing. Thus we find no evidence to support the assumption that a moratorium period, or delayed transitions, are associated with increased levels of wellbeing. Too few - or too many unsupported transitions (as in the case of the 'fragile families') are not beneficial for wellbeing. Engaging in developmentally appropriate transitions, even if they might be perceived as 'risky' (as in the case of early parenthood), can open up opportunities for young people to experience competence and accomplishment, as illustrated in the case of 'traditional families'. The timetable for achieving certain transition markers appears to be variable and depends on the resources available to the individual. Family background, gender, individual capabilities and preferences play an important role in shaping transition behaviours, and young people have to balance demands and resources.

In interpreting the findings, one has to be aware of a principal limitation of latent class analysis, which lies in the temptation to attach too much meaning to a latent class or the label assigned to it (Sandefur et al 2005). One has to remain cautious in interpreting the group allocations, especially in regard of reifying labels assigned to the classes for easier interpretations. The final model provides only a summary of the many ways in which role configurations may occur in society. For both cohorts, the five key status indicators had been measured at age 26. In the 1958 cohort, however, the outcomes have been collected seven years later. It is possible that changes in role combinations have occurred in that time period, as the role configurations of cohort members in their mid-20s only represent a snapshot in time, and do not capture the dynamics of transition processes. However, being able to compare the associations between role combinations and indicators of subjective wellbeing for the two cohorts, reveals a similar pattern in associations between transition experiences, antecedents and associated outcomes. Future research should control for prior levels of wellbeing, and use latent transition analysis to study changes in class membership and associated outcomes over time (Macmillan and Copher 2005; Macmillan and Eliason 2003; Oesterle et al 2010). The analyses presented here, provide evidence of changes and similarities in role combinations in two birth cohorts born 12 years apart and regarding their antecedents and associated outcomes, contributing to a better understanding about the interdependencies of transitions to adult roles in times of social change. The results show heterogeneity and persistent social structuring of transition experiences. There is a differentiation between fast versus slow transitions, with young people from less privileged backgrounds being less likely to participate in higher education than their more privileged peers, and women making the step into family formation earlier than men.

Not all young people follow the same script, and there are five distinct groups characterized by different role combinations at age 26 . The majority of young people in both British cohorts were attached to the labour market and have established a committed relationship. Changes in life course patterns are only slight between the two cohorts, and in both cohorts we could identify five comparable groups. The level of wellbeing across these five groups appears to depend less on the timing of transitions, but on the developmental match of transition demands and individual resources and capabilities, as illustrated by the 'traditional family' group who successfully navigated all five role transitions by age 26 . The life course perspective and latent class approach provide a better understanding of consistency and change in the way new social roles combine in individual lives, and provide useful information about how to support young people in their transition to independence. 


\section{Acknowledgements}

The analysis and writing of this article were supported by grants from the UK Economic and Social Research Council (ESRC): RES-594-28-0001, the ESRC Centre for the Study of Life-chances and Learning in the Knowledge Economies (Llakes); the US National Science Foundation Grant No. 0818478, and the National Institute on Alcohol Abuse and Alcoholism (HD44138). Data from the Cohort Studies were supplied by the ESRC Data Archive. Those who carried out the original collection of the data bear no responsibility for its further analysis and interpretation. Any opinions, findings, and conclusions or recommendations expressed in this material are those of the author(s) and do not necessarily reflect the views of the National Science Foundation or the ESRC.

\section{References}

Arbuckle JL. (1996) Full information estimation in the presence of incomplete data. In GA Marcoulides and RE Schumacker. eds. Advanced Structural Equation Modelling: issues and techniques. Lawrence Erlbaum Associates, Mahwah, NJ.

Amato P and Booth A. (1997) A generation at risk: Growing up in an era of family upheaval. Harvard University Press, Cambridge, Mass.

Arnett JJ. (2000) Emerging adulthood. A theory of development from the late teens to the late twenties. American Psychologist, 55, 469-480.

Asparouhov T and Muthén, B. (2009) Exploratory structural equation modeling. Structural Equation Modeling, 16, 397-438.

Baltes PB. (1990) Life-span developmental-psychology - basic theoretical principles. Psychologische Rundschau, 41, 1-24.

Beck $U$ and Beck-Gernsheim E. (2002) Individualization. Institutionalized individualism and its social and political consequences. Sage, London.

Birdwell J, Grist M and Margo J. (2011) The forgotten half. Demos, London.

Blossfeld HP. (2005) Globalization, uncertainty and youth in society. London, Routledge.

Booth A, Rustenbach E and McHale S. (2008) Early family transitions and depressive symptom changes from adolescence to early adulthood. Journal of Marriage and Family, 70, 3-14.

Bronfenbrenner U. (1979) The ecology of human development : Experiments by nature and design. Harvard University Press, Cambridge, MA.

Buchmann M. (1989) The script of life in modern society: Entry into adulthood in a changing world. Chicago University Press, Chicago.

Bynner J. (2001) British youth transitions in comparative perspective. Journal of Youth Studies, 4, 5-23.

Bynner J. (2005) Rethinking the youth phase of the life course: The case for emerging adulthood. Youth and Society, 8, 367-384.

Clogg C. (1995) Latent class models. In G Arminger, C Clogg and M Sobel. eds. Handbook of statistical modeling for the social and behavioural sciences. Pp. 311-359. Plenum Press, New York.

Cohen P, Kasen S, Chen H, Hartmark C and Gordon K. (2003) Variations in patterns of developmental transitions in the emerging adulthood period. Developmental Psychology, 39, 657-669.

Dias JG and Vermunt JK. (2006) Bootstrap methods for measuring classification uncertainty in latent class analysis. Springer, New York.

Eccles JS, Lord SE, Roeser RW, Barber BL and Hernandez-Jozefowicz DM. (1997) The association of school transitions in early adolescence with developmental trajectories through high school. In JE Schulenberg, JL Maggs and K Hurrelmann. eds. Health risks and developmental transitions during adolescence. Pp 283-320. Cambridge University Press, New York.

Elder GH. (1998) The life course as developmental theory. Child Development, 69, 1-12.

Elder GH, Johnson KM and Crosnoe R. (2004) The emergence and development of life course theory. In JT Mortimer and MJ Shanahan. eds. Handbook of the life course. Pp. 3-19. Springer, New York.

Elder GH and Shanahan MJ. (2007) The life course and human development. In The handbook of child psychology. 6th edition. Wiley, New York.

Ferri E, Bynner J, Bynner and Wadsworth M. (2003) Changing Britain, changing lives: Three generations at the turn of the century. Institute of Education, London.

Furlong A and Cartmel F. (1997) Young people and social change. Open University Press, Buckingham.

Furstenberg FF. (2000) The sociology of adolescence and youth in the 1990s: A critical commentary. Journal of Marriage and the Family, 62, 896-910. 
Garrett JL and Eccles JS. (2009) Transition to adulthood: Linking late-adolescent lifestyles to family and work status in the mid twenties. In I Schoon and KR Silbereisen. eds. Transitions from school to work: Globalisation, individualisation, and patterns of diversity. Pp 243-264. Cambridge University Press, New York.

Giddens A. (1991) Modernity and self-identity: Self and society in the late modern age. Polity Press, Cambridge.

Goodman L. (1974) Explanatory latent structure analysis using both identifiable and unidentifiable models. Biometrika, 61, 215-231.

Halperin S. ed. (1998). The Forgotten Half revisited: American youth and young families, 1988-2008. American Youth Policy Forum, Washington, DC.

Heckhausen J. (1999) Developmental regulation in adulthood: Age-normative and sociostructural constraints as adaptive challenges. Cambridge University Press, Cambridge.

Heinz WR. (2002) Transition discontinuities and the biographical shaping of early work careers. Journal of Vocational Behavior, 60, 220-240.

Henretta JC. (2007) Early childbearing, marital status, and women's health and mortality after age 50. Journal of Health and Social Behavior, 48, 254-266.

Jones G. (2002). The youth divide: Diverging paths to adulthood. Joseph Rowntree Foundation, York.

Keeton C P, Perry-Jenkins M and Sayer AG. (2008) Sense of control predicts depressive and anxious symptoms across the transition to parenthood. Journal of Family Psychology, 22, 212-221. doi: 10.1037/0893-3200.22.2.212

Kiernan K. (1997) Becoming a young parent: a longitudinal study of associated factors. British Journal of Sociology, 48, 406-428.

Kins E and Beyers W. (2010) Failure to Launch, Failure to Achieve Criteria for Adulthood? Journal of Adolescent Research, 25, 743-777. doi: 10.1177/0743558410371126

Lazarsfeld P and Henry N. (1968) Latent structure analysis. Houghton Mifflin, Boston.

Leete R and Fox J. (1977) Registrar General's social classes: Origins and users. Population Trends, 8, 1-7.

Lesthaeghe R. (1995) The second demographic transition in western countries: An interpretation. In KO Mason and AM Jenson. eds. Gender and family change in industrialised countries. Pp 17-62. Clarenden Press, Oxford.

Macmillan R and Copher R. (2005) Families in the life course: Interdependency of roles, role configurations, and pathways. Journal of Marriage and the Family, 67, 858-879.

Macmillan R and Eliason S. (2003) Characterizing the life course as role configurations and pathways: A latent structure approach. In JT Mortimer and MJ Shanahan. eds. Handbook of the life course. Pp 529-554. Plenum, New York.

Magnusson D, Bergmann LR and El-Khouri BM. (2003) Studying individual development in an interindividual context. A person-oriented approach. Lawrence Erlbaum, Mahwah, N J and London.

McGee R, Williams S and Silva PA. (1986) An Evaluation of the Malaise Inventory. Journal of Psychosomatic Research, 30, 147-152.

Muthén LK and Muthén BO. (2007). Mplus user's guide. 5th edition. Muthén and Muthén, Los Angeles, CA.

Nomaguchi KM and Milkie MA. (2003) Costs and rewards of children: The effects of becoming a parent on adults' lives. Journal of Marriage and Family, 65, 356-374. doi: 10.1111/j.1741-3737.2003.00356.x

Nylund KL, Asparouhov T and Muthen, B. (2007) Deciding on the number of classes in latent class analysis and growth mixture modeling. A Monte Carlo simulation study. Structural Equation Modeling, 14, 535-569.

Oesterle S, Hawkins JD, Hill KG and Bailey JA. (2010) Men's and women's pathways to adulthood and their adolescent precursors. Journal of Marriage and Family, 72, 1436-1453.

Osgood DW, Ruth G, Eccles JS, Jacobs JE and Barber BL. (2005) Six paths to adulthood. In RA Settersten Jr, FF Furstenberg and RG Rumbaut. eds. On the frontier of adulthood. Theory, research and public policy. Pp 320-355. The University of Chicago Press, Chicago.

Plewis I, Calderwood L, Hawkes D and Nathan G. (2004) National child development study and 1970 British cohort study. Technical report: Changes in the ncds and bcs70 populations and samples over time. Institute of Education, Centre for Longitudinal Studies, London.

Rodgers B, Pickles A, Power C, Collishaw S and Maughan B. (1999) Validity of the malaise inventory in general population samples. Social Psychiatry and Psychiatric Epidemiology, 34, 333-341.

Ross A, Schoon I, Martin P and Sacker A. (2009). Family and nonfamily role configurations in two British cohorts. Journal of Marriage and the Family, 71, 1-14.

Rutter M, Tizard J and Whitmore K. (1970). Education, health and behavior. Longmans, London.

Rutter M and Madge N. (1976) Cycles of disadvantage: a review of research. Heinemann Educational Books, London.

Sandefur GD, Eggerling-Boeck J and Park H. (2005). Off to a good start? Postsecondary education and early adult life. In RA Settersten, Jr, FF Furstenberg and RG Rumbaut. eds. On the frontier of adulthood. Theory, research and public policy. Pp 356-395. The University of Chicago Press, Chicago. 
Schoon I. (2007) Adaptations to changing times: Agency in context. International Journal of Psychology, 42, 94-101.

Schoon I. (2008) A transgenerational model of status attainment: The potential mediating role of school motivation and education. National Institute Economic Review, 205, 72-82.

Schoon I, Martin P and Ross A. (2007) Career transitions in times of social change. His and her story. Journal of Vocational Behavior, 70, 78-96.

Schoon I, Ross A and Martin P. (2009) Sequences, patterns, and variations in the assumption of work and family related roles. Evidence from two British birth cohorts. In I Schoon and KR Silbereisen. eds. Transitions from school to work: Globalisation, individualisation, and patterns of diversity. Pp. 219242). Cambridge University Press, New York.

Schoon I and Silbereisen KR. eds. (2009) Transitions from school to work: Globalisation, individualisation, and patterns of diversity. Cambridge University Press, New York.

Schulenberg JE, Bryant AL and O'Malley PM. (2004) Taking hold of some kind of life: How developmental tasks relate to trajectories of well-being during the transition to adulthood. Development and Psychopathology, 16, 1119-1140.

Schulenberg JE and Maggs JL. (2002) A developmental perspective on alcohol use and heavy drinking during adolescence and the transition to young adulthood. Journal of Studies on Alcohol, Supplement 14, 54-70.

Schulenberg JE, O'Malley PM, Bachman JG and Johnston LD. (2005) Early adult transitions and their relation to well-being and substance use. In RA Settersten Jr, FF Furstenberg and RG Rumbaut. eds. On the frontier of adulthood. Theory, research and public policy. Pp 417-453. The University of Chicago Press, Chicago.

Schulenberg JE, Sameroff AJ and Cicchetti D. (2004) The transition to adulthood as a critical juncture in the course of psychopathology and mental health. Development and Psychopathology, 16, 799-806.

Schwarz G. (1978) Estimating the dimension of a model. The Annals of Statistics, 6, 461-464.

Seiffge-Krenke I and Gelhaar T. (2008) Does successful attainment of developmental tasks lead to happiness and success in later developmental tasks? A test of Havighurst's (1948) theses. Journal of Adolescence, 31, 33-52.

Shanahan MJ. (2000) Pathways to adulthood in changing societies: Variability and mechanisms in life course perspective. Annual Review of Sociology, 26, 667-692.

Shanahan MJ, Porfeli EJ, Mortimer JT and Erickson LD. (2005). Subjective age identity and the transiton to adulthood: When do adolescents become adults? In RA Settersten Jr, F Furstenberg and RG Rumbaut. eds. On the frontier of adulthood. Theory, research and public policy. Pp. 225-255. The University of Chicago Press, Chicago.

Staff J, Schulenberg JE, Maslowsky J, Bachman JG, O'Malley PM, Maggs JL and Johnston LD. (2010) Substance use changes and social role transitions: Proximal developmental effects on ongoing trajectories from late adolescence through early adulthood. Development and Psychopathology, 22, 917-932.

Symonds WC, Schwartz RB and Ferguson R. (2011) Pathways to Prosperity: Meeting the Challenge of Preparing Young Americans for the 21st Century. Harvard Graduate School of Education, Harvard. http://www.gse.harvard.edu/news events/features/2011/Pathways to Prosperity Feb2011.pdf.

Umberson D, Pudrovska T Reczek C. (2010) Parenthood, Childlessness, and Well-Being: A Life Course Perspective. Journal of Marriage and the Family, 72, 612-629. doi: 10.1111/j.17413737.2010.00721.x

Woo $\mathrm{H}$ and Raley RK. (2005) A small extension to "Costs and rewards of children: The effects of becoming a parent on adults' lives". Journal of Marriage and Family, 67, 216-221. doi: 10.1111/j.00222445.2005.00016.x 